\title{
Tratamiento legal de las tradicionales uniones de hecho y tercer género
}

Elisa Muñoz-Catalán*

Doctora en Derecho. Profesora acreditada Universidad de Huelva, Huelva, España. Correo electrónico:

elisa.munoz@dthm.uhu.es

Recibido: 17 de diciembre del 2015

Aprobado: 4 de mayo del 2016

Cómo citar este artículo: Elisa MuñozCatalán. Tratamiento legal de las tradicionales uniones de hecho y tercer género. DIxI 24. Octubre 2016. Pág. 127. doi: http://dx.doi. org/10.16925/di.v18i24.1527

\section{Resumen}

Introducción: en nuestros días, analizar el fundamento legal de las tan frecuentes uniones de hecho, el origen de este tipo de prácticas y sus consecuencias para el ordenamiento jurídico supone profundizar en un ámbito algo desconocido si tenemos presente que nos encontramos en una época de posible crisis en la familia tradicional. Metodología: por tal razón, investigaremos cómo la ausencia de los presupuestos básicos, especialmente la capacidad jurídica o conubium, incidía en las relaciones extramaritales y cuál fue, en suma, la razón de ser de las prohibiciones al llamado desde la Roma clásica como iustum matrimonium frente al matrimonio legítimo. Resultados: defenderemos seis criterios para agrupar el gran número de uniones extramatrimoniales que se sucedieron, destacando: el concubinato, el contubernio, la homosexualidad, el matrimonio incestuoso, simulado o entre ausentes, las uniones con sujetos que carecían de capacidad física, el adulterio o la prostitución. Conclusiones: se concluye con una breve mención a la influencia ideológica de los emperadores, el cristianismo y la normativa sobre relaciones intersexuales y tercer género, aprobada recientemente en Europa.

Palabras clave: capacidad, extramarital, intersexuales, matrimonio, uniones de hecho. 


\title{
The Legal Treatment of Traditional De Facto Marriages and Third Gender
}

\begin{abstract}
Introduction: Current analysis of the legal basis for the frequent de facto marriages and both the origin of these practices and their implications for the legal system supposes delving into a rather unknown area, bearing in mind that we are living in a time of possible crisis for the traditional family. Methodology: For this reason, we will investigate how the absence of basic assumptions-especially legal capacity, or conubium-influenced extramarital relationships. We will also investigate what was, in short, the raison dêtre of the prohibitions of the designation on the part of classical Rome of legitimate marriage as iustum matrimonium. Results: We defend six criteria for grouping together the large number of extramarital unions that followed, highlighting: concubinage; cohabitation; homosexuality; incestuous marriage, sham marriage, and marriage between absent parties; unions with parties who lacked the physical capacity for marriage; adultery; and prostitution. Conclusions: We conclude with a brief mention of the ideological influence of the emperors, Christianity, and regulations on intersexual and third gender relationships, recently approved in Europe.
\end{abstract}

Keywords: capacity, extramarital, intersex, marriage, de facto marriage

\section{Tratamento legal das tradicionais uniões de fato e terceiro gênero}

\section{Resumo}

Introdução: em nossos dias, analisar a base jurídica das tão frequentes uniões de fato, a origem desse tipo de práticas e suas consequências para o ordenamento jurídico supõe aprofundar num âmbito desconhecido se levarmos em consideração que nos encontramos numa época de possível crise na família tradicional. Metodologia: por essa razão, pesquisaremos como a ausência dos pressupostos básicos, especialmente a capacidade jurídica ou conubium, incidia nas relações extraconjugais e que foi, em suma, a razão de ser das proibições ao chamado, desde a Roma Clássica, como iustum matrimonium perante o matrimonio legítimo. Resultados: defenderemos seis critérios para agrupar o grande número de uniões extraconjugais que se sucederam, destacando: o concubinato, o contubérnio, a homossexualidade, o matrimônio incestuoso, simulado ou entre ausentes, as uniões com sujeitos que careciam de capacidade física, o adultério ou a prostituição. Conclusões: conclui-se com uma breve menção à influência ideológica dos imperadores, do cristianismo e da normativa sobre as relações intersexuais e terceiro gênero, aprovada recentemente na Europa.

Palavras-chave: capacidade, extraconjugal, intersexuais, matrimônio, uniões de fato. 


\section{INTRODUCCIÓN}

Recientemente, Alemania se ha convertido en el primer país europeo en reconocer legalmente la existencia del llamado "tercer sexo o género" entre aquellos sujetos intersexuales considerados como tal porque, desde un punto de vista médico, presentan ambigüedad genital o poseen lo que se conoce como un sexo indiferente, esto es, que tanto física como biológicamente muestran caracteres propios del sexo femenino y del masculino ${ }^{1}$.

De hecho, la normativa aprobada en noviembre del 2013 por el país germano surgió tras los resultados de un estudio llevado a cabo previamente por el Consejo Alemán de Ética, el cual determinó que, aun hoy y en pleno siglo xxI, la legislación de la Unión Europea no garantiza expresamente el goce o disfrute de los derechos humanos y fundamentales de las personas intersexuales en condiciones de igualdad, respecto de quienes no lo son. Motivado, quizás, por el rechazo y marginación social que los sujetos con dicha deformidad han sufrido a lo largo de la historia (de hecho, desde la antigua Roma se prefirió emplear la voz hermafrodita en lugar del moderno término "intersexual", puesto que el primero aludía a la unión de Hermes y Afrodita, dioses griegos representativos de lo masculino y lo femenino). En última instancia, creemos que las tradicionales lagunas legislativas en esta materia igualmente se pueden deber a la inexistencia de una definición jurídica que identifique de forma homogénea $y$, a su vez, englobe a estos seres humanos de sexo algo indefinido.

Es en este punto en el que entendemos que tiene razón de ser el presente trabajo, mediante el que pretendemos ofrecer una aproximación al origen y regulación jurídica de la gran diversidad de uniones extra-conyugales, esporádicas o meramente sexuales que en Roma no cumplían con los presupuestos esenciales de capacidad física y de capacidad jurídica o conubium como para considerarlas un matrimonio romano legal, eficaz y con plenos derechos, o un iustum matrimonium a efectos del Derecho romano clásico y de mayor esplendor. Esto al aportar a tal efecto

1 Para un estudio más detallado de estos conceptos clínicos, véase Adriana Agramonte Machado. Tratamiento quirúrgico de los genitales ambiguos: fundamentos e implicaciones psicológicas y sexuales. Revista Cubana de Endocrinología 17(3). Sep-dic. 2006. Disponible en http://scielo.sld.cu/scielo.php?script=sci_arttext\&pid=S1561-29532006000300004 Véase también Francisca Ugarte y Carolina Sepúlveda. Estudio del recién nacido con ambigüedad genital y gónadas palpables. Revista CHILENA DE PEDiATRíA 78(6). 2007. Págs. 578-583. Disponible en http://www.scielo. $\mathrm{cl} / \mathrm{pdf} / \mathrm{rcp} / \mathrm{v} 78 \mathrm{n} 6 / \mathrm{art} 02 . \mathrm{pdf}$ una serie de criterios o principios que nos pueden ayudar a sistematizar las cerca de treinta relaciones esporádicas de carácter extramatrimonial diferentes que se dieron durante la existencia del orden romano.

Se debe tener presente, en todo caso, que no resulta fácil conceptualizar ni el propio matrimonio, pues para su definición legal originaria debemos acudir a las escasas fuentes jurídicas ${ }^{2}$ que de algún modo aluden a esta institución familiar, configurándola como la unión consentida y libre de dos personas de sexo distinto, capaces desde un punto de vista físico y jurídico, con la intención de formar un consorcio continuado y recíproco para toda la vida, siempre que se respetase, por una parte, el elemento objetivo u honor matrimonii que significaba una convivencia exteriorizada entre los contrayentes; y, por otra, el elemento subjetivo e intencional calificado como la affectio maritalis, la cual representaba la intención o voluntad mutua y perpetuada de los cónyuges para tenerse como marido y mujer. A contrario sensu, cuando no se daban dichos requisitos y, de forma paralela al vínculo marital, surgían las antes mencionadas uniones extramatrimoniales de carácter puramente ocasional, parejas de hecho o relaciones sine conubio, cuyo número fue aumentando progresivamente en el Imperio romano ante la dificultad para obtener el conubium, ius conubii, la capacidad jurídica o, en términos generales, el derecho al matrimonio. Por tal razón, y siguiendo los estudios llevados a cabo por el profesor Robleda ${ }^{3}$, a lo largo de nuestra exposición demostraremos cuáles son esos elementos definitorios de las relaciones sexuales conformadas a pesar de la inexistencia del conubium y de la capacidad física o natural de las esposos.

Cabe señalar, en primer lugar, que debía tratarse de uniones inestables o esporádicas cuya consideración jurídico-social dependiera de la condición jurídica de los sujetos que se unían, como era el caso del concubinato, el contubernio, las relaciones homosexuales, los matrimonios contra mandata, entre ausentes o las uniones entre patricios y plebeyos. De igual forma, extra-familiares fueron aquellas relaciones en las que no existía la capacidad física de las partes, ya fuesen castrados, esterilizados, ancianos, dementes, locos (furiosus) o matrimonios contraídos por menores de edad.

En tercer término, estas parejas de hecho se podían caracterizar por no respetar los vínculos

\footnotetext{
2 Cf. D. 23, 2, 1 (Mod. 1 reg.); Cf. IJ. 1,9,1.

Cf. Olís Robleda. El matrimonio en Derecho Romano. ESENCIA, REQUISITOS DE VALIDEZ, EFECTOS, DISOLUBILIDAD. Università Gregoriana. (1970). Pág. 276.
} 
familiares existentes, como en el supuesto de los matrimonios incestuosos, el ligamen, la consanguinidad o los matrimonios contraídos sin que la viuda respetase el tempus lugendi. Se consideraban relaciones extra-conyugales, a la postre, aquellas otras en las que no existía un consentimiento mutuo libremente prestado entre hombre y mujer, o este estaba de algún modo viciado, aludiendo así a los matrimonios simulados, por miedo o por violencia, las uniones maritales viciadas por error o dolo, y los matrimonios informes dada la ausencia de formalidad o solemnidad al momento de celebrarse.

Finalmente, detendremos nuestra atención en aquellas otras uniones de hecho que tampoco respetaban el principio monogámico propio del iustum matrimonium, como en los casos de adulterio, bigamia, prostitución o lenocinio. A estos supuestos se le añadirán, desde época posclásica y justinianea, otros casos que claramente reflejaban la influencia del cristianismo en el Imperio romano, como eran las relaciones contra legem entre un tutor y su pupila, el rapto, las uniones con colonos de baja condición social, la disparidad de religión entre judíos y cristianos, los vínculos conformados existiendo un parentesco espiritual y, también, el orden sagrado o el voto de castidad como límites a tales uniones.

\section{LA HETEROGENEIDAD DE UNIONES}

\section{EXTRAMATRIMONIALES DESDE ROMA}

Como adelantábamos anteriormente, a continuación presentamos un elenco de las relaciones extra-conyugales que surgieron en Roma y que se caracterizaron todas ellas por la falta de conubium o ausencia del derecho al matrimonio, así como por no cumplir con el resto de requisitos clásicos exigidos para considerarlos un iustum matrimonium, dada la incapacidad jurídica que las partes presentaban. Todo lo cual, sin lugar a dudas, conllevaba la existencia de otro tipo de relaciones menos reguladas o incluso ilícitas o prohibidas, desde la etapa clásica hasta la posclásica o justinianea, con la llegada del cristianismo y su posterior influjo en emperadores romanos tales como Constantino I o Justiniano.

A fin de comprender el fundamento legal de este tipo de prácticas esporádicas debemos partir de las siguientes premisas generales. En primer término, señalar como, dado que las relaciones sine conubio fueron numerosas, se plantea la dificultad de aportar una categorización legal completa de todas ellas, pues las fuentes son escasas y regulan la materia de manera fragmentaria o parcial, de tal forma que determinadas uniones extramaritales solo se abordaron desde el Derecho posclásico y con el advenimiento de las ideas cristianas, obviándose de este modo el periodo clásico o preliminar. De lo anterior se deriva el hecho de que, aun cuando se ha pretendido abordar esta materia desde diferentes ámbitos, creemos que tampoco se ha sabido ofrecer una clasificación clara y sistemática de todas ellas, razón por la cual nuestra tarea consiste en integrar e interpretar los textos, analizando su evolución clásica hasta la presencia de Justiniano en el Imperio romano.

En tercer lugar, cabe recordar que, a lo largo de nuestro estudio hemos hecho uso de los términos impedimento, prohibiciones, restricciones o limitaciones al matrimonio justo de forma indiferente, aludiendo en general a su significado literal, esto es, como meros obstáculos o inconvenientes a contraer un matrimonio conforme a las reglas del Derecho romano ${ }^{4}$, dada la ausencia de conubium y siempre teniendo en cuenta el origen canónico de dicho vocablo.

Todas esas uniones extra-conyugales venían delimitadas, a su vez, por dos categorías genéricas con efectos jurídicos similares entre sí, pero distintos de los matrimonios romanos clásicos. Nos referimos, en cualquier caso, al matrimonio ilegítimo inexistente (matrimonium iniustum non potest) considerado como tal por haber sido contraído en defecto un consentimiento mutuo entre las partes, englobando el matrimonio del demente, el matrimonio simulado o el matrimonio por miedo, así como aludimos al matrimonio ilegítimo ineficaz (matrimonium iniustum nullum) por contravenir las exigencias legales y por no contar con presupuestos tan esenciales como fue el conubium, agrupando en este segundo supuesto el matrimonio informe, el matrimonio contra mandata y las uniones ilícitas con mujer adúltera.

Pues bien, bajo las premisas anteriores, pasamos a detallar cuáles son esos seis criterios básicos que hemos utilizado con la intención de aglutinar y ordenar los caracteres propios de cada una de esas uniones no matrimoniales y contra legem que se dieron en Roma: (a) la consideración jurídico-social ${ }^{5}$ : en

\footnotetext{
4 Con relación al alcance legal de los mencionados impedimentos al matrimonio y las uniones de hecho nos remitimos a un trabajo previo de la autora, véase Elisa Muñoz-Catalán. Controversias jurídicas en torno a los impedimentos romanos y la intersexualidad. rJuam. Revista Jurídica de la Universidad Autónoma de MADRID 29. 2014

5 En general, refiriéndonos a la condición social como causa impeditiva del matrimonio en Roma, véase Franceso Maria De Robertis. La condizione sociale e gli impedimenti al matrimonio nel Basso Imperio. AnNali Bari 4. 1939. Págs. 45-69.
} 
efecto, en el siguiente apartado de nuestro trabajo se analizarán una serie de prácticas que tenían como punto en común la consideración de los que se unían ilícitamente, por lo que este nos sirve como primer principio clasificatorio. Concretamente, a este primer grupo pertenecen las relaciones extra-familiares por concubinato, contubernio, las uniones entre homosexuales, aquellas otras formadas entre patricios y plebeyos, los matrimonios contra mandata, los vínculos fuera del matrimonio con persona deportada, desterrada a una isla desierta u oasis, o ausente por causa del servicio militar; (b) el principio de la capacidad física o natural de las partes ${ }^{6}$ : este segundo criterio que hemos manejado, por su lado, tenía en cuenta si mediaba o no la capacidad física de los que se unían, por lo que dedicaremos otro epígrafe de nuestra investigación a detallar las relaciones sine conubio con castrados, esterilizados, impotentes o ancianos, y aquellas otras uniones carentes de la capacidad jurídica necesaria por la falta de capacidad mental y demencia del loco o furious; (c) conforme a los vínculos familiares existentes: como tercer criterio y, bajo el mismo epígrafe anterior, analizaremos las uniones extra-conyugales por incesto, ligamen, consanguinidad, así como las relaciones sine conubio de la viuda que no hubiera respetado el tiempo de luto o tempus lugendi, dada la posible mezcla de sangres que de ello se podía derivar.

En último apartado de nuestro estudio, detallaremos de forma conjunta los tres criterios que faltan, los cuales nos servirán de cierre al presente trabajo: (d) el criterio que tiene en cuenta la existencia o no de consentimiento por parte de los sujetos que se unían: señalándose específicamente los matrimonios simulados, los matrimonios por miedo o los matrimonios informes; (e) a lo que se añade, en quinto lugar, el criterio relativo al respeto al matrimonio monogámico y a los principios de la moral romana: diferenciándose entre el adulterio, la prostitución y el lenocinio; y finalmente (f), según la influencia ideológica que ejercieran los emperadores romanos: veremos el criterio que distingue entre aquellas relaciones prohibidas por Augusto por ir contra la legislación matrimonial, como, por ejemplo, las uniones entre senadores y mujeres turpes, y aquellas otras limitadas por el emperador Constantino y más tarde por

\footnotetext{
6 Por lo que respecta al fundamento jurídico o razón de ser de la ausencia de facultades naturales como uno de los seis criterios clasificatorios defendidos por la autora en este ámbito, véase Elisa Muñoz-Catalán. El matrimonio romano en ausencia de facultades físicas: Demencia, senectud y minoría de edad. e-SLEgAL History REVIEW 18. (2014).
}

Justiniano, como los casos de parentesco espiritual, el orden sagrado o el voto de castidad.

De forma comparativa y en aras de complementar o justificar nuestra sistematización, nos interesa examinar brevemente la clasificación ofrecida por el profesor Ghirardi ${ }^{7}$, quien de forma general enumeró las distintas clases de uniones extra-familiares. Precisamente, el autor las califica directamente de uniones sexuales, actos sexuales contra natura y relaciones carnales consentidas llevadas a cabo al margen del matrimonio legítimo, en las que el sujeto activo generalmente era un hombre y el sujeto pasivo variaba considerablemente. En este sentido, diferencia unos diez tipos de prácticas sexuales ilegales que pasamos a nombrar: 1. El adulterio, siempre que un hombre tuviese relaciones consentidas con una mujer casada, pues ello estaba penado por la Ley Iulia de Adulteriis Coercendis; 2. El estupro, cuando un hombre tenía relaciones sexuales consentidas con una mujer viuda o una doncella de similar o superior posición social a la suya; 3 . El estupro con otro hombre; y 4 . El concubinato producido cuando un hombre tenía relaciones sexuales consentidas y estables con una mujer de baja extracción social o una liberta, con la cual, carecía de ius connubium y le era imposible por ese motivo contraer matrimonio y tener affectio maritalis. Sobre este último, aclara que se trataba de una relación de rango inferior al matrimonio pero lícita, si bien:

A partir del advenimiento del Cristianismo se tendió a mirarlo con disfavor, dado que la Iglesia primitiva enseñaba que la única manera de vida en común posible era dentro de una familia, fundada sobre la base de la unión matrimonial. Como el concubinato se salía de este molde, fue despreciado, además de considerárselo un pecado que ofendía el sexto mandamiento ${ }^{8}$.

A lo anterior se añaden el resto de relaciones que comprenden la sistematización defendida por este autor, a saber: 5 . La prostitución, pero matizándose que cuando un hombre alternase con prostitutas este no cometía acto reprobable alguno a efectos del Derecho romano, ni era causa de divorcio; 6 . La violación o rapto si un hombre sometía por la fuerza a una mujer o a otro hombre contra la voluntad de estos, ya que era autor responsable de violación, si bien como el

\footnotetext{
Cf. Juan Carlos Ghirardi. Regulación jurídica de las conductas sexuales extramatrimoniales en el Derecho Romano. RGDR. REVISTA General de Derecho Romano 5. 2005. Pág 9.

$8 \quad$ Véase Juan Carlos Ghirardi, supra, nota 7.
} 
mismo Ghirardi señala9: "Durante mucho tiempo no existió legislación específica que se refiriese a la violación, de manera que solamente debe haber cabido la posibilidad de perseguirla conforme la forma y penalidades establecidas para el delito de iniuria"; 7. El acoso sexual, cuando un hombre sin llegar al acceso carnal provocaba a una mujer libre cometiendo el delito de iniuria y normalmente violando, a su vez, el edicto de Adtemptata Pudicitia ${ }^{10}$, dado el atentado al pudor que perpetraba; 8 . Cometían incesto aquellos hombres que mantenían relaciones sexuales con su pupila o con una parienta en grado próximo de parentesco, conllevando la nulidad del matrimonio contraído y sanciones penales; 9. Contubernio, pues en esta unión intervenían esclavos, ya fuesen estos entre sí o con alguna otra persona libre, pero no incurrían en conducta reprochable alguna, y tal actitud tampoco justificaba que su mujer solicitase el divorcio o lo repudiase. Como nos advierte textualmente el profesor, si el esclavo era ajeno incurría con el dueño en el delito de daño y caía dentro de las previsiones de la Ley Aquilia, se podía ejercitar contra él la acción pretoria de corrupción de esclavo. 10. Sobre los casos de homosexualidad femenina, finalmente, cabe decir que las uniones lésbicas entre mujeres no fueron reguladas expresamente por el Derecho romano, si bien el autor concluye su intervención admitiendo que ello: "No implica que no existiesen, y sin perjuicio de que las mismas, si resultaban escandalosas, podrían dar lugar a la correspondiente acción de injurias, por parte del o de los ofendidos"11.

Dejando al margen los distintos principios clasificatorios que hemos dado a conocer, cabe recordar las dos dificultades fundamentales que se plantean en este ámbito, pues salvo instituciones más reguladas como el concubinato, el contubernio, o las uniones introducidas por la legislación matrimonial de Augusto, no contamos con fuentes jurídicas o literarias suficientes que nos ayuden en la tarea de investigar esas uniones extra-familiares. Por lo tanto, debemos acudir a las diversas interpretaciones textuales y opiniones doctrinales existentes al respecto a fin de entender el verdadero alcance de cada relación. La segunda dificultad a la que hacemos frente es que

\footnotetext{
9 Id. Págs. 35-36.

10 En cuanto a la regulación que hace este edicto en materia de acoso, véase María José Bravo Bosch. Algunas consideraciones sobre el Edictum de Adtemptata ad pudicitia. AAVv, ACTAS DEL II Congreso Iberoamericano de Derecho Romano. (1998). Págs. 41-53. Véase también Dora Delapuerta Montoya. Estudio sobre el Edictum de Adtemptata Pudicitia. Tirant Lo Blanch. (1999); y Juan Carlos Ghirardi, supra, nota 7. Págs. 38-39.

11 Véase Juan Carlos Ghirardi, supra, nota 7. Pág. 10.
}

las últimas uniones extra-conyugales a causa de la tutela, el rapto, el colonato, la disparidad de religión entre judíos y cristianos, el parentesco espiritual y por orden sagrado o voto de castidad, serán objeto de estudio desde su existencia en la Roma posclásica, dada la escasez de textos anteriores que regulen dichos supuestos, eliminándose de este modo cualquier mención al periodo clásico anterior o de mayor esplendor.

Por lo expuesto, no solo la falta de conubium determinó desde la época clásica el nacimiento de una prohibición matrimonial, sino que a este requisito de carácter negativo se le podían unir otros también importantes, como fueron la ausencia de capacidad física o natural entre las partes, la inexistencia de un consentimiento recíproco entre los contrayentes o el incumplimiento del principio monogámico, entre otros. Lo que tendrá su reflejo en los tipos de uniones extramatrimoniales sine conubio que presentamos y desarrollamos en las siguientes líneas de este artículo.

\section{LA CONSIDERACIÓN SOCIAL \\ ANTE EL CONCUBINATO Y OTRAS RELACIONES SIMILARES}

Comenzamos este apartado de nuestro trabajo tomando como punto de referencia el primer criterio que hemos defendido previamente, es decir, aquel relativo a la consideración jurídica y social de los futuros esposos, pues el mismo nos sirve hoy para articular las uniones extramatrimoniales sine conubio que se englobaban bajo esa distinción. En este punto, podemos confirmar que el concubinato se conformaba como la relación más frecuente en el imperio, pues presentaba un carácter estable y era admitido socialmente, si bien su reconocimiento fue variando a lo largo de las distintas etapas de vigencia del Derecho romano; pasando de ser una figura de hecho reconocida por el Derecho clásico, hasta considerarse como una institución jurídica con plenos efectos ya desde la época posclásica con los emperadores romanos cristianos y, especialmente, en lo que respecta al emperador Justiniano.

Concretamente, esta primera relación fáctica o de hecho se producía libremente entre un hombre y una mujer cuando no existía una mutua intención de estar vinculados legalmente a través del matrimonio $y$, en general, faltaban los requisitos esenciales, siendo la ausencia de la affectio maritalis o el consensus entre las partes el elemento que marcaba la diferencia entre 
el matrimonio y el concubinato; por tal razón, se han venido calificando de uniones para-matrimoniales y de uniones o parejas de hecho por ser similares o a imitación del matrimonio romano aun faltando el elemento volitivo, así como por estar perfectamente diferenciadas de las uniones transitorias o voluptuosas, y de las meras relaciones sexuales esporádicas.

En este ámbito, hemos partido de la etapa clásica puesto que es cuando la legislación matrimonial del emperador Augusto comenzó a regular por escrito el concubinato, otorgándole ciertos efectos jurídico-sociales. A modo de ejemplo cabe citar la Lex Iulia de adulteriis, la cual castigaba como delito las uniones sexuales producidas fuera del matrimonium y las consideraba adulterium o strupum, a la vez que ofrecía toda una sistematización de aquellas mujeres de clase social inferior con las que se podía tener relaciones sin incurrir en las penas previstas para el adulterio o estrupo, refiriéndonos a las meretrices, las actrices condenadas en juicios públicos, las esclavas o las libertas ${ }^{12}$. Aunque no tenían honestas, lo cierto es que con estas mujeres era posible la unión extra-conyugal estable por no ser penalmente punible.

Sobre la evolución de esta figura, hemos concluido que si bien Constantino I quiso proteger las uniones legales y honestas ordenando su conversión en matrimonio con la finalidad de obstaculizar el concubinato, lo cierto es que dicho emperador no alcanzó su objetivo y este tipo de relaciones extramaritales comenzó a adquirir desde entonces una mayor importancia aumentando su número de forma considerable. Cabe destacar que el concubinato fue reconocido, posteriormente, por el emperador cristiano Justiniano como una inaequale coniugium, esto es, una unión lícitamente contraída y monogámica pero de carácter inferior al matrimonio, requiriéndose la misma edad que para el matrimonio y sujetándose a los mismos impedimentos de parentela consanguínea, por adopción o afinidad. En consecuencia, a diferencia de lo que ocurrió desde la época clásica con Augusto, el emperador Justiniano hizo más fácil el acceso al matrimonio legalmente conformado, por lo que las uniones concubinarias fueron desapareciendo paulatinamente en el Imperio romano.

En segundo término, hemos incluido dentro de ese primer principio el contubernio, ya que desde la etapa clásica se conformó como un tipo frecuente de relación sine conubio, de carácter inestable y con un reconocimiento más social que jurídico que se

12 Cf. D. 25,7,1,1 (Ulp. 2 ad Leg. Iul. et Pap.): Cum Atilicino sentio et puto solas eas in concibinatu habere posse sine metu criminis, in quas strupum non committitur. producía entre esclavos, entre una persona libre y un esclavo, ampliándose este segundo supuesto al caso en el que el cónyuge que había contraído un matrimonio iustum caía en cautiverio y se hacía servus. Sin embargo, conviene matizar que en la última etapa de la historia de Roma el emperador Justiniano derogó toda relación inestable y carente de conubium entre eslavos o personas libres y esclavos, favoreciendo de este modo los matrimonios legítimos entre esclavos y mujeres libres con la intención de que los súbditos del emperador adquiriesen la libertad ${ }^{13}$.

Mención especial requiere el alcance jurídico de otra de las uniones extra-conyugales sine conubio que también hemos encuadrado en función de la consideración jurídico-social de las partes: aludimos a la homosexualidad y a las relaciones lésbicas. Dada la influencia de la cultura griega que sufrió Roma durante la etapa republicana, no es de extrañar el gran número de relaciones ilícitas que se produjeron entre personas del mismo sexo y que tenían los mismos órganos sexuales ${ }^{14}$, y cuyo fin último no era la procreación sino la mera satisfacción sexual y el placer, siempre teniendo presente que existía una clara incapacidad física para contraer matrimonio romano válido, dado que en este tipo de prácticas las dos partes compartían un mismo género u órganos sexuales. Con el emperador Augusto estas experiencias sexuales continuaron ejercitándose aumentando el número de ciudadanos bisexuales; sin embargo, las relaciones homosexuales entre mujeres se consideraron la peor de las depravaciones, calificándose en los textos literarios de uniones lésbicas contra natura y criminales ${ }^{15}$.

Referente a los matrimonios contra mandata, en cuarto lugar, cabe decir que se trataba de un tipo de matrimonio nullum e ineficaz dada la falta de voluntad recíproca de las partes de formar un iustum matrimonium, que en época clásica lo conformaban aquellas uniones carentes de ius conubii por haber sido contraídas entre magistrados, funcionarios o soldados que ejercían su profesión u oficio en las provincias y aquellas mujeres nacidas o domiciliadas

13 Cf. Miguel Falçao. LAS prohibiciones matrimoniales DE CARÁCTER SOCIAL EN EL IMPERIO Romano. Universidad de Navarra. (1973). Pág. 79. El profesor Falçao finaliza este apartado referido al Derecho Justinianeo, señalando que: "En resumen: No hay, ciertamente, matrimonio entre persona libre y otra esclava; pero, con tal que el consorte esclavo adquiera la libertad, existe matrimonio como entre ingenuos".

14 Saara Lilja. Homosexuality in Republican and Augustan Rome. Societas Scientiarum Fennica. (1983). Págs. 15 y ss.

15 Véase Juan Carlos Ghirardi, supra, nota 7. Págs. 9-10. 
en dicho lugar. Entendemos que el fundamento de la ausencia del derecho al matrimonio en estos supuestos y el nacimiento de una unión extramarital por razón del cargo público del varón, tanto en época clásica como posteriormente, se encuentra en primer lugar en tratar de salvar la libertad matrimonial de la mujer domiciliada o nacida en dicha provincia, ante la posibilidad de que algún funcionario tratase de aprovechar su cargo para imponerle el matrimonio ${ }^{16}$, así como lo anterior también se debía a un intento por evitar que el matrimonio del officium gerens con mujer de familia prestigiosa de la provincia tuviese como finalidad acabar con su profesión. Como consecuencia de dicha prohibición los matrimonios contra mandata fueron nulos o jurídicamente inexistentes haciéndose solo legítimo tras cesar el cargo, por lo que sus hijos tenían la consideración jurídica de ilegítimos.

En cuanto a los matrimonios por deportación, subrayar que ese destierro impedía la formación de un matrimonio romano válidamente constituido debido a la estancia involuntaria del desterrado a una isla u oasis con la consiguiente pérdida de los derechos de ciudadanía y, en caso que existiera una relación entre el deportado a una isla y una mujer libre, esta unión sería calificada como extramatrimonial y sine conubio por razón de la expatriación. Concretamente, en la etapa clásica la deportación suponía un obstáculo al iustum matrimonium no solo por la falta de los derechos propios atribuidos a los ciudadanos romanos, sino también por la ausencia del ius conubii. Sin embargo, desde la llegada al poder del emperador Constantino I y luego con Justiniano, este exilio comenzó a no disolver el vínculo marital dejando de ser causa de impedimento si ya había sido contraído previamente ${ }^{17}$.

Por lo que respecta al matrimonio inter absentes a causa del servicio militar, hemos concluido que, hasta finales del siglo II d.C., el cumplimiento del servicio militar impedía el matrimonio romano legalmente contraído al entenderse que de esta manera se mantenía la disciplina en el ejército. No obstante lo anterior, los escasos testimonios con los que contamos nos llevan a no admitir este impedimento como tal, fundamentando dicha tesis negativa en el hecho de que en época clásica los soldados podían continuar con su matrimonio si estos habían sido contraídos antes de ser reclutados en el servicio militar o, incluso, formar uno nuevo, siempre que no fuese con mujeres oriundas o domiciliadas en la provincia donde prestasen el servicio. Desde el periodo posclásico, el emperador Constantino I (año 337 d.C.) trató de romper con la tradición clásica de restringir las posibilidades que tenía la uxor de contraer un nuevo matrimonio en el supuesto de ausencia del marido a causa del servicio militar, pues ya la mujer podía unirse en segundas nupcias sin caer en adulterio y sin que ello le supusiera la pérdida de la dote. Esto era posible si se cumplían dos requisitos esenciales que evitaban la calificación de estos matrimonios como clandestinos, esto es, que hubieran transcurrido al menos cuatro años sin tener noticia de su marido y sin posibilidad de habere iudicium, así como hacía falta notificar al $d u x$ del marido su intención de contraer un nuevo matrimonio. Pues bien, como demostró el profesor Biondi ${ }^{18}$, se trataba de un derecho singular para buscar la seguridad de la muerte del primer marido.

Cerrando este criterio clasificatorio hemos aludido, a la postre, a las uniones entre patricios y plebeyos justificando su inclusión en el hecho de ser dos clases sociales muy diferenciadas que, al final, consiguieron contraer un matrimonio libre; en cuanto a su reconocimiento desde los orígenes del imperio, decir que si bien la Ley de las XII Tablas había prohibido específicamente el ius conubii entre ambos órdenes sociales por considerarlas relaciones inhumanas, lo cierto es que las luchas patricio-plebeyas hicieron que a partir de mediados del siglo v a.C. (445 a.C.), con la Rogatio Canuleia del tribuno Canuleyo, se consiguiera que el gobierno patricio aceptara el derecho al matrimonio y la validez de las uniones entre patricios y plebeyos, concediéndoseles el ius conubii y aceptándose la ausencia de limitaciones legales a las uniones maritales.

En todo caso, podemos concluir admitiendo que desde el año 445 a.C. patricios y plebeyos pudieron contraer matrimonio por la Lex Canuleia, pero no se sabe con certeza si fueron muchas las uniones maritales legalmente conformadas o, por contra, desde finales de la Monarquía y principios de la República disminuyeron; lo que sí podemos confirmar es que desde el periodo clásico y, especialmente en el posclásico, estos vínculos fueron desapareciendo dado que apenas contamos con textos que regulen dicha cuestión.

18 Véase Biondi Biondo. Il Diritto Romano CRISTIANo III. Giuffrè. (1954). Pág. 154. 


\section{VÍNCULOS FAMILIARES}

\section{Y MEZCLA DE SANGRE}

El siguiente criterio que hemos tomado como referencia a fin de categorizar estas prácticas sexuales es el de las uniones extra-conyugales sine conubio en razón de la capacidad física o natural de las partes. En primer lugar, se ha reparado en el supuesto de los castrados (castrati), esterilizados (spadones) y ancianos (senes), quienes en principio presentaban cierta impotencia para engendrar y, por ese motivo, tenían limitado su derecho a contraer matrimonio legítimo en Roma. En estos casos, existía cierta incapacidad física que obstaculizaba la validez del matrimonio romano clásico, pues recordemos que el matrimonium iustum exigía la capacidad natural, la capacidad jurídica, la convivencia marital, y una intención recíproca y continuada de vivir en comunidad para perpetuar la especie ${ }^{19}$.

Por último, nos hemos planteado si durante el Derecho clásico existió este impedimento o nació con el emperador Justiniano, dado que ciertos textos de la compilación justinianea reflejan la impotencia de los castrati, mientras que otros pasajes aluden a los estériles o naturalmente incapaces, concluyendo a tal efecto que si bien estas limitaciones al matrimonio surgieron durante la época clásica, su regulación legal expresa aparece con Justiniano, quien consideraba como impotentes y, por ende, en ausencia de conubium a los castrati, pero no así a los estériles o naturalmente incapaces generand $i^{20}$.

Asimismo, hemos reunido en este segundo principio las relaciones del furiosus, el mente captus y el demens ${ }^{21}$. Hacemos referencia, en términos generales, a la persona demente que había sido privada de juicio por razón de su enajenación mental, por lo que esa ausencia de capacidad natural hacía que el individuo se viese afectado por una incapacidad de obrar absoluta, y le llevara a una verdadera enfermedad que le impedía unirse maritalmente ${ }^{22}$; de hecho, si temporalmente recobraba el juicio, el Derecho romano

19 Cf. D. 23, 2, 1 (Mod. 1 reg.); Cf. también IJ. 1, 9, 1.

20 Cf. Danilo Dalla. L'Incapacità sessuale in Diritto Romano.

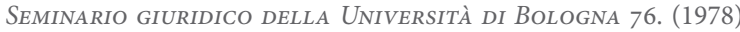
Págs. 246, 250 y 288.

21 Recordemos que para un estudio más preciso de estos supuestos, véase Elisa Muñoz Catalán, supra, nota 8. Págs. 4-18.

22 Centrándonos en el alcance y protección del que padecía una enfermedad mental, véase María Lourdes Martínez de Morentín Llamas. De la cura furiosi en las XII Tablas, a la protección del disminuido psíquico en el Derecho Actual (A propósito de la sts de 20 de noviembre de 2002). RgDr. Revista General De Derecho Romano 4. 2005. Págs. 5, 8 y ss. entendía que estaba capacitado para realizar ciertos actos jurídicos pero no para contraer matrimonio, pues este derecho requería la plena capacidad física y jurídica de las partes en el momento de contraer el vínculo marital ${ }^{23}$. En cuanto a la evolución jurídica de estas prácticas sexuales, en el Derecho justinianeo se restringió este concepto al demente con momentos de lucidez, frente al demens o mente captus afectado de locura permanentemente y, por esto, solamente tenía capacidad legal en los momentos conocidos como “intervalos lúcidos", es decir, cuando temporalmente recobraba la salud mental.

Sobre el matrimonio de la menor en Roma, partimos de la premisa general de que uno de los fines principales del matrimonio romano era la procreación, por tanto, en principio, no podían contraerlo aquellas personas que no hubiesen alcanzado la pubertad por carecer de la madurez sexual suficiente para tener descendencia. Sin embargo, se ha venido añadiendo ${ }^{24}$ la posibilidad de que la mujer contrajese matrimonio incluso antes de los doce años que marcaban la pubertad, fijándose el límite mínimo de los siete años de edad si era viri potens, es decir, capaz de soportar físicamente el ser poseída por un hombre.

De otro lado, y ya centrándonos en el tercer criterio clasificatorio relativo a los vínculos familiares existentes como límite al matrimonio romano, es preciso señalar el caso de los matrimonios incestuosos y clandestinos entre parientes. En este sentido, cabe resaltar que el pueblo romano, según el propio R. Astolfi ${ }^{25}$, rechazó de forma absoluta las relaciones entre parientes anulando el matrimonio incestuoso e imponiendo penas al que se hubiera unido en un matrimonio clandestino, como era el caso de la deportatio in insulam, sanción propia de la época clásica. De este modo, la ausencia de conubium a causa del parentesco entre los sujetos que formaban una relación afectiva se configuró en la Roma clásica como una limitación matrimonial en razón del vínculo familiar existente entre hombre y mujer que compartían una misma sangre, hecho que conllevaba la calificación de relación extra-familiar, mientras que, por su lado, la legislación posclásica retomó las sanciones contra el incesto y reprimió fuertemente los delitos sexuales, en particular lo que respecta a este último.

A continuación, hemos examinado el ligamen y la exigencia de divorcio ante el doble vínculo.

\footnotetext{
23 Cf. D. 50, 17, 40 (Pomp. 34 ad sab.).

24 Cf. Riccardo Astolfi. Il matrimonio nel Diritto Romano Classico. Cedam. (2006). Págs. 238 y ss.

25 Id. Págs. 94 y ss.
} 
Pues bien, desde la época clásica y en especial en el periodo posclásico, la formación de una segunda relación preexistiendo un matrimonio anterior no disuelto hacía que esa unión fuera considerada como extra-conyugal, ilícita y no permitida por el Derecho romano, dado el ligamen que existía con el primer vínculo matrimonial. Debemos tener en cuenta que el matrimonio romano fue esencialmente monogámico y la existencia de un vínculo matrimonial no disuelto se entendía como una limitación matrimonial debido a dos motivos fundamentales: la ausencia de ius conubii entre las partes, y la antinaturalidad que suponía la existencia de un doble vínculo, independientemente de la condición o profesión de la persona que pretendía contraer dos matrimonios.

Teniendo en cuenta que el divorcio del primer vínculo dejó de ser libre a partir del Derecho posclásico $\mathrm{y}$, muy especialmente con el emperador Justiniano, ello hizo incrementar el número de relaciones extra-conyugales sine conubio por existencia de doble vínculo en el imperio, tal y como se recoge en los textos justinianeos que abordan este impedimento, y los cuales literalmente sostienen que el ligamen al menos desde época posclásica impedía el matrimonio ${ }^{26}$. Pues bien, ante esto hemos concluido nuestra investigación defendiendo que la existencia de un matrimonio anterior solo constituyó impedimento matrimonial como tal desde el periodo posclásico, cuando el matrimonio estaba basado en un consentimiento meramente inicial.

Dentro de este grupo hemos englobado, en último lugar, el supuesto del tempus lugendi y la mezcla de sangre como prohibiciones matrimoniales a la viuda. Aludimos a aquellas uniones extramatrimoniales sine conubio que se producían cuando la viuda, no respetando el tiempo de luto, había vuelto a contraer un nuevo matrimonio. Desde los orígenes del Derecho romano existía una imposibilidad para que la viuda pudiera contraer un segundo matrimonium iustum antes delos diez meses siguientes a la muerte del primer marido, tratando así de evitar posibles dudas sobre un embarazo posterior y la mezcla de sangre (partus o turbatio sanguinis). De hecho, desde la etapa clásica, las personas que no respetaban este periodo sufrían una limitación al matrimonio romano justo, y solo podían formar una unión extra-familiar dada la posible mezcla de sangres y la incertidumbre ante una posible paternidad. En cuanto al Derecho posclásico y el influjo cristiano cabe destacar por último que, además de exigirse los doce meses o annus lugendi, también se requería que esta limitación al iustum

26 Cf. IJ. 1, 10, 6; Cf. también IJ. 1,10,7. matrimonium recayera tanto sobre la viuda, como sobre la divorciada ${ }^{27}$.

\section{Consentimiento, MORAL}

\section{ROMANA Y CRISTIANISMO}

En este epígrafe de nuestra exposición, estudiaremos los tres últimos criterios que nos sirven de cierre a la sistematización que hemos llevado a cabo a lo largo de nuestro estudio, detallando aquellas relaciones sine conubio producidas sin consentimiento, no respetando el principio monogámico del matrimonio o aquellas otras que tuvieron lugar por la ideología de los emperadores romanos en cada periodo de la historia de Roma, en especial, en lo que respecta a la etapa clásica, posclásica y justinianea.

Pues bien, en primer lugar y dependiendo de si mediaba o no consentimiento de los sujetos, hemos distinguido entre los matrimonio simulados, caracterizándolos como aquellos vínculos contraídos entre personas entre las que no había un consentimiento verdadero como para formar una familia y procrear, sino todo lo contrario, la intención real era la de beneficiarse de las ventajas que se daba a los matrimonios dentro de las Leyes de Augusto ${ }^{28}$. Estas relaciones, también denominadas como "matrimonios de complacencia" o "uniones a cambio de un precio", se consideraban como relaciones extramatrimoniales sine conubio por razón de la simulación y la ausencia de affectio maritales, siendo supuestos de inexistencia jurídica al surgir una discordancia entre las voluntades declaradas por los que se unían y las intenciones que verdaderamente eran queridas; no existiendo, en ningún caso, una pretensión real de convivir en una sociedad conyugal ni una voluntad continuada de formar una familia, lo que finalmente conllevaría al divorcio.

De igual modo, destacamos los matrimonios contraídos por miedo o violencia por tratarse de aquellas uniones cuasi-maritales llevadas a cabo en Roma contra la voluntad de al menos uno de los cónyuges y que, al igual que ocurría en los matrimonios simulados, también se producía una inexistencia del consentimiento efectivo y real, pero a causa del miedo o el temor producido por la amenaza y la coacción.

\footnotetext{
27 Cf. Nov. 22, 40.

28 En tema de matrimonio romano y, concretamente sobre la importancia de que existiese una voluntad real de unirse perpetuamente en un consortium omnis vitae, véase Biondi Biondo, supra, nota 18. Pág. 101.
} 
Este tipo de para-matrimonios por miedo (metus) o por violencia (vis) se caracterizaba por la fuerza material y física o la violencia externa que había que ejercer para que una de las partes contrajese el vínculo marital, no consistiendo en un mero temor o coacción ${ }^{29}$. A nuestro parecer, el matrimonio romano clásico no podía ser contraído bajo coacción, ya que era un derecho que debía ser aceptado libremente, pues la finalidad principal era formar un consorcio para toda la vida y perpetuar la especie, de la misma forma que en el periodo posclásico tampoco fueron válidos dichos matrimonios y se consideraron como no contraídos debido a la concepción del consensus como meramente inicial.

Mención individual requieren los matrimonios viciados por error o dolo, ya que en línea con el anterior supuesto, nos encontramos con un tipo especial de matrimonio iniustum considerado como tal por estar viciada o modificada la voluntad de al menos uno de los futuros esposos. El problema principal de estas uniones conocidas como "matrimonios por error" o "matrimonios por dolo" son los escasos textos que abordan la materia, pues dificulta la tarea de determinar a lo largo de nuestra investigación cuál es la esencia de este tipo de uniones extramatrimoniales sine conubio en época clásica, e impedimentos matrimoniales ya en el periodo posclásico ${ }^{30}$. De esta forma, retomamos los estudios llevados a cabo por el profesor Astolf ${ }^{31}$ sobre estas prácticas, el cual sostuvo que estos matrimonios eran nulos debido al error en la identidad del cónyuge, conformándose en Roma como un claro impedimento al matrimonio legal.

En fin, cabe decir que pertenecen también a este cuarto criterio los casos de matrimonios informes. Nos referimos, en general, a una forma ad solemnitatem que cumplía todo matrimonio romano contraído válidamente y que si no se verificaban tales elementos formales, se consideraban ilegítimos, no firmes y carentes de efectos aun cuando no ineficaces ${ }^{32}$. Mientras el Derecho romano arcaico exigía ciertas solemnidades para contraer matrimonium, lo cierto es que ya desde época clásica los vínculos maritales pudieron ser contraídos libremente y de cualquier

29 Cf. D. 4, 2, 21, 5 (Paul. 11 ad edict.); Cf. también D. 23,2,21 (Terent. Clem. 3 ad Leg. Iul. et Pap.). y D. 23,2,22 (Cel. 15 dig.).

30 Cf. D. 3, 2, 1 (Iul. 1 ad edict.). Cf. también D. 23, 2, 43, 10 (Ulp. 1 ad Leg. Iul. et Pap.).

31 Cf. Riccardo Astolfi, supra, nota 24. Págs.102-103.

32 Cf. D. 23, 2, 2 (Paul. 35 ad edict.). Cf. D. 23, 2, 6 (Ulp. 35 ad sab.). Cf. D. 23, 2, 18 (Iul. 16 dig.). Cf. también D. 23, 2, 21 (Terent. Clem. 3 ad Leg. Iul. et Pap.). Cf. D. 23, 2, 22 (Cel. 15 dig.). Cf. D. 23, 2, 25 (Mod. 2 reg.). Cf. también D. 23, 2, 30 (Gai. 2 ad Leg. Iul. et Pap.); $y$ D. 23, 2, 35 (Pap. 6 resp.). forma, puesto que el matrimonio romano era un hecho con relevancia social y lo que importaba era la existencia de un consentimiento mutuo continuado, así como la capacidad jurídica y física de los cónyuges ${ }^{33}$.

De otra parte, y aludiendo ahora al quinto criterio clasificatorio que diferenciaba los casos que afectaban a la moral romana y al principio monogámico del matrimonio, hemos distinguido en primer término el supuesto del adulterio y la bigamia. En este sentido, hemos definido el matrimonio romano como esencialmente monogámico, por lo que no cabría hablar de una tercera persona ajena o un cómplice en dicha relación conyugal, pues desde los comienzos del Imperio romano se rechazaron las uniones maritales bígamas. En la etapa arcaica, el varón que sufría el adulterio por parte de su esposa podía castigarla a través del iudicium domesticum o procedimiento privado excepcional, en el cual se consultaba al paterfamilias y demás parientes, los cuales formaban un consejo de familia. Ya con las leyes matrimoniales de Augusto, se sustituyó por el iudicium moribus, considerándose el adulterio como una limitación al matrimonio dada la falta de conubium entre los contrayentes para conformar un matrimonio justo, calificándose generalmente como de impedimentum criminis y, ante esto, el adulterium pasó a ser un crimen público perseguido a instancias del marido o del padre de la adúltera, así como de cualquier ciudadano si ellos no lo hacían transcurridos dos meses desde el divorcio. En cuanto a su evolución posterior cabe comentar que no será hasta Constantino I, y especialmente con el emperador Justiniano, cuando este impedimento se establece como prohibición expresa entre la adúltera y el cómplice por influencia del cristianismo, extendiéndose incluso hasta después de la muerte del marido y castigándose el adulterio con la pena capital ${ }^{34}$.

Este penúltimo principio también aglutinaría los casos de prostitución y lenocinio, por ser unas prácticas muy habituales en Roma. La Lex Iulia de adulteriis castigaba como adulterium o stuprum toda unión sexual fuera del matrimonio, existiendo diferentes categorías de mujeres con respecto a las cuales era posible tener relaciones sexuales sin incurrir en pena alguna, por lo que se trataba ${ }^{35}$ de aquellas mujeres consideradas probosae o turpes y carentes de honestidad con las que sí se podía contraer concubinato y a las que nunca se les podría denominar

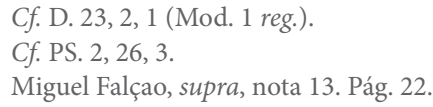


materfamilias. Dentro de este grupo nos encontramos, en suma, con las mujeres esclavas (servus), las actrices (scaenica) y las condenadas en juicio público, las adúlteras sancionadas, las mujeres que habían violado la fidelidad matrimonial y las sorprendidas en adulterio, así como las obscuro loco natae, es decir, las hijas de actores o actrices cuyo origen fue oscuro y poco honorable. Por último, no podemos olvidar a las libertas, las meretrices o amantes (meretrix), las prostitutas (corpore quaestum faciens) o exprostitutas, y las alcahuetas o seductoras (lenas).

Para terminar, y cambiando de tercio, aludimos al sexto y último criterio tomado como referencia para dividir las distintas uniones extra-conyugales, refiriéndonos a aquel que tiene en cuenta la ideología de los emperadores a lo largo de las distintas etapas de la historia de Roma. Sobre las uniones no consideradas por Augusto como matrimonio secundum Legem Iuliam et Legem Papiam Poppaeam, en primer lugar, hemos retomado la importancia de la Lex Iulia de maritandis ordinibus (18 a.C.) y la Lex Papia Poppaea (9 d.C.) promulgadas por el emperador Augusto con el nombre de Lex Iulia et Papia Poppaea, cuya finalidad era restaurar la familia romana sobre la base de las tradiciones, a fin de desarrollar una política legislativa que favoreciese tanto las uniones matrimoniales lícitamente contraídas, como la procreación. Por esta norma, todos los ingenuos, salvo los senadores y sus descendientes, podían contraer matrimonio con los libertos, eliminando cualquier impedimento al matrimonio originado por la distinta clase o la condición social.

Si bien no nos encontramos con fuentes que indiquen el origen de estos impedimentos, y menos aún que defiendan que estas limitaciones naciesen con las leyes matrimoniales de Augusto, nosotros hemos mantenido que la ausencia de conubium relativo y de tipo social se dio en los siguientes supuestos, los cuales pasaban a formar parte de las conocidas como "uniones concubinarias". En primer lugar, en los matrimonios entre senadores, sus hijos y ulteriores descendientes hasta el tercer grado (hasta los bisnietos), tanto ellos como ellas por una parte, y libertinas, personas de teatro o hijos de personas de teatro, artistas o hijas de artistas y prostitutas, por la otra. Esto en razón de de evitar la mezcla de clases y conseguir que la raza se conservase pura. Con la misma intención de evitar la mezcla de sangre estaban vetados los vínculos contraídos entre ingenuos, fueran o no de la clase senatorial, con personas que practicaban el lenocinio, prostitutas, las condenadas en juicio como adúlteras (adúlteras flagrantes) y artistas de teatro.
A nuestro juicio y, en tercer lugar, existió este tipo de impedimento al matrimonio romano legal en tiempos de Augusto en aquellos matrimonios entre un liberto y su patrona, o el liberto y la que hubiera sido uxor del patrono (o la hija del mismo), así como en las uniones estables o convivencia entre un ciudadano romano y una latina o peregrina carente de la civitas, o en los matrimonios entre un cives y las libertas. Asimismo, era nulo el matrimonio del interdicto y del demente por la falta de capacidad de obrar que existía en este tipo de unión e, igualmente, los hijos de familia requerían el consentimiento del pater para contraer matrimonio porque, en caso contrario, el matrimonio contraído sería nulo. En suma, hemos concluido este tipo de uniones asegurando que la carencia de conubium en aquellos supuestos regulados por primera vez con las leyes de Augusto, pasaron a ser considerados como impedimentos relativos y de carácter social durante la existencia del Derecho romano posclásico, ya que estos siguieron en vigor hasta la época del emperador Constantino, quien extendió la lista de mujeres con las que los senadores (u otros altos cargos dignatarios como los perfectissimi, duoviri municipales, o sacerdotes provinciales) no podían contraer matrimonio dada la baja condición social de estas, como, por ejemplo, con una mujer liberta o de humilde nacimiento.

El segundo grupo de uniones extramaritales que pertenecían a este último criterio que nos sirve de cierre a nuestra clasificación, es el relativo a las relaciones sine conubio surgidas desde la Roma posclásica por la influencia del cristianismo. Observamos las uniones ilícitas entre tutor y pupila ${ }^{36}$ resaltando expresamente que, de acuerdo con un senadoconsulto de los tiempos de Marco Aurelio y Cómodo (175 y 180 d.C.), se prohibió el matrimonio entre tutor y pupila antes de rendir cuenta sobre la administración de sus bienes y en tanto que no se extinguiese el plazo para intentar una restitutio in integrum por la minoría de edad, de forma que el impedimento se extendía también al pater del tutor y a sus descendientes. Respecto a la evolución jurídica de este supuesto, desde época posclásica, esta prohibición se extendió a los hijos y nietos del tutor, los hijos adoptivos de este siempre que estuvieran bajo su potestad, el padre del tutor y sus herederos aunque fuesen extraños, pues se creía que todos ellos conformaban uniones carentes de conubium por razón del cargo público del tutor ${ }^{37}$.

36 Véase Paola Borrelli. Il divieto di matrimonio tra tutore e pupilla. labeo. Rassegna di Diritto Romano 43. 1997. Págs. 365-389.

37 Cf. D. 23,1,15 (Mod. libr. sing. de enucleatis casibus). Cf. D. 23,2,36 (Paul. 5 quaest.). Cf. D. 23,2,37 (Paul. 7 resp.); Cf. D. 23,2,59 (Paul libr. sing. de assignat. libert.); Cf. D. 23, 2, 60, 5 (Paul. libr. 
De la misma manera, el rapto se configuró como una limitación matrimonial introducida en la etapa posclásica a causa del arrebato de una doncella núbil, casada o viuda, sin su previo consentimiento o el de sus padres, aunque ya la Lex Iulia de adulteriis coercendis había prohibido el matrimonio entre el raptor y la mujer raptada, según la propia romanística ${ }^{38}$. Sobre las uniones con colonos de baja condición social, por su parte, decir que si bien los denominados impedimentos matrimoniales por colonato se regularon específicamente en Roma a partir del emperador Justiniano, lo cierto es que desde época posclásica comenzaron a surgir las denominadas uniones extramatrimoniales por impedimento de colonato entre una mujer libre y un colono ajeno (coloni adscripticii o servi glebae). Sin embargo, como Robleda ${ }^{39}$ nos recuerda, tal prohibición solo era aplicada a los colonus pero no a los esclavos, ya que al esclavo no se le prohibía el matrimonio.

En cuanto a la disparidad de religión entre judíos y cristianos, es preciso subrayar que hasta la Roma clásica las creencias religiosas no supusieron un impedimento para no celebrar el iustum matrimonium, ya que se tenía una especial tolerancia por los cultos de los pueblos extranjeros, de tal modo que muchos de ellos los practicaban; resultando muy común, a comienzos de la época imperial, el hecho de que las mujeres romanas se sintieran atraídas por los cultos en adoración a la diosa egipcia Isis. No obstante, las persecuciones en contra de los cristianos tuvieron un motivo político más que religioso, ya que atentaban contra las costumbres romanas por ir en contra de la esclavitud y por no prestar adoración a la figura del emperador, el cual era considerado como una divinidad al igual que lo eran los dioses.

Así, la diversidad de religiones desde la etapa posclásica pasó a conformarse como una verdadera limitación al matrimonio iustum dadas las luchas políticas e ideológicas entre judíos y cristianos, motivo por el cual los cristianos no pudieron contraer matrimonio con personas de otra religión o culto y, en caso de hacerlo, se conformaban como uniones extramatrimoniales sine conubio por disparidad de religión entre estos. Tal tipo de unión perduró hasta la etapa de Justiniano, quien en el año 556 d.C. suprimió

sing. ad orat. divi Antonini et Commodi); Cf. D. 23,2,64,1 (Callist. 2 quaest.). Cf. D. 23, 2, 67, 3 (Thryph. 9 disputat.). Cf. D. 23, 2, 67, 4 (Thryph. 9 disputat.)

38 Con relación al rapto y la Lex Iulia de adulteriis, véase Biondi Biondo, supra, nota 18. Pág. 93 y ss. Cf. Olís Robleda, supra, nota 3. Pág. 209.

39 Cf. Olís Robleda, supra, nota 3. Pág. 276. la pena capital de la adúltera por la pena de la vida monástica.

En línea con los casos analizados, el parentesco espiritual o religioso también impidió el matrimonio en época del emperador Justiniano, dada la relación existente entre las partes ${ }^{40}$. Con la llegada del cristianismo al imperio no podían ser un matrimonio romano legal, y formaban parte de las calificadas de uniones sine conubio, las relaciones entre el padrino y la ahijada, dado el vínculo establecido por el bautismo entre el bautizado y sus padrinos y madrinas, a pesar de que se podían unir maritalmente madrina y ahijado. Por último, se ha abordado la naturaleza de este tipo de impedimento por cognación espiritual, admitiéndose que fue el emperador Justiniano el primero que lo configuró como matrimonio sacrílego e incestuoso teniéndolo por no celebrados, por lo que los hijos habidos en tales uniones adquirían la consideración de espurios (spurii) o lo que hoy se conoce como bastardos.

A fin de completar lo anterior, hacemos una breve alusión al orden sagrado y al voto de castidad como límites matrimoniales. En efecto, dentro de esta última tipificación se encuadran aquellas uniones sine conubio que Justiniano prohibió que se denominasen como matrimonium dado el orden sagrado (los cuerpos constituidos en sentido civil, es decir, el cuerpo de los que gobernaban), o el voto de castidad (simbolizaba la renuncia abierta a una vida marital con otra persona y el no tener relaciones sexuales por el voto público y solemne contraído con la institución religiosa). Desde tiempo posclásico se había ido reconociendo progresivamente dicha limitación, pero no fue hasta el año 531 d.C. cuando Justiniano ${ }^{41}$ expresamente declaró que, tanto el orden sagrado como el voto de castidad, se conformaban como impedimentos matrimoniales en los que el emperador aplicó la doctrina canónica al Derecho romano.

\section{Conclusiones}

A modo de conclusión, finalizamos nuestra exposición afirmando que la escasez de estudios que tradicionalmente han abordado de una forma sistemática e íntegra la diversidad de uniones extramatrimoniales o relaciones esporádicas reconocidas desde el propio Derecho romano, justifican la presente investigación.

40 Cf. CJ. 5, 4, 26, 2.

41 Cf. CJ. 1, 3, 52, 14. 
Entendemos que una mera lectura del título del mismo, esto es, el Tratamiento legal de las tradicionales uniones de hecho y tercer género, nos lleva a reparar en las diferencias que presentaba desde época clásica el iustum matrimonio con plenos efectos, con relación a aquellas otras numerosas parejas ilegítimas surgidas durante la etapa de mayor esplendor del imperio, por no cumplir con los presupuestos esenciales exigidos legalmente. Se destaca en este punto la carencia del requisito de la capacidad física, la inexistencia del conubium o capacidad jurídica de las partes, así como la falta de un consentimiento mutuo y continuado entre los que se unían libremente en un consorcio para toda la vida, tal y como las escasas o fragmentarias fuentes con las que contamos establecen a la hora de delimitar el matrimonio romano ${ }^{42}$.

Ante la inexistencia de una clasificación doctrinal más o menos homogénea que aglutine tal diversidad de parejas de hecho, como se ha demostrado previamente (algunas meramente se limitan a enumerarlas sin seguir un criterio fijo o estructurado ${ }^{43}$ ), hemos visto necesario agrupar las cerca de treinta uniones sexuales sine conubio presentes desde la antigüedad romana bajo seis criterios o principios que, a nuestro parecer, por primera vez clasifican e integran de forma innovadora estas relaciones tan frecuentes. Se diferencian, específicamente, entre los siguientes supuestos: (a) la consideración jurídico-social de los que se unen ilícitamente ${ }^{44}$, distinguiendo entre el concubinato, el contubernio, la homosexualidad, las uniones con patricios y plebeyos, los matrimonios contra mandata, con persona deportada a una isla o ausente por cumplir con el servicio militar; (b) el principio de la capacidad física o natural de las partes, encuadrando los casos de relaciones sine conubio con castrados, esterilizados, impotentes o ancianos, y con sujetos que presentaran falta de capacidad mental o demencia; (c) conforme a los vínculos familiares existentes, cabría citar las uniones extra-conyugales por incesto, ligamen, consanguinidad, o aquellas en las que la viuda no hubiese respetado el tiempo de luto marcado por el Derecho romano para evitar mezcla de sangres; (d) en lo que alude al criterio que tiene en cuenta la existencia de consentimiento, reunimos a los matrimonios simulados, por miedo o aquellos matrimonios informes; (e) sobre el respeto o no al matrimonio monogámico y los principios de la moral romana, se diferencia entre uniones de facto, adulterio, prostitución o lenocinio; (f) finalmente, según el

42 Cf. D. 23, 2, 1 (Mod. 1 reg.). Cf. también IJ. 1,9,1.

43 Cf. Juan Carlos Ghirardi, supra, nota 7. Págs. 9 ss.

$44 C f$. Franceso Maria De Robertis, supra, nota 5. Págs. 45 y ss. pensamiento o ideología de los distintos emperadores romanos, cabe citar aquellas relaciones prohibidas por Augusto por ir contra de su legislación matrimonial, como las uniones entre senadores y mujeres turpes, y aquellas otras limitadas posteriormente por los emperadores cristianos Constantino y Justiniano, como, por ejemplo, las uniones bajo parentesco espiritual, orden sagrado o voto de castidad.

A lo anterior cabría añadir, en último término, un vínculo sexual surgido desde la primitiva Roma bajo el término originario de "hermafrodita", pero que hoy se presenta como sinónimo de "intersexual"; nos estamos refiriendo a aquellas uniones extramatrimoniales sine conubio presentes en el imperio y conformadas por sujetos con cierta ambigüedad genital o malformaciones, las cuales podríamos agrupar tanto en el primer criterio que hemos defendido previamente relativo a la consideración jurídico-social de los que se unen, como en el segundo principio que hemos manejado, en aras de concretar aquellas otras relaciones en las que al menos uno de los cónyuges carecía de la capacidad física o natural exigida para el matrimonio legal. La razón de su estudio no es otra que el reciente y progresivo reconocimiento legal que están teniendo desde los distintos ordenamientos jurídicos europeos aquellas uniones con sujetos intersexuales, es decir, aquellas personas que como hemos definido desde el comienzo de nuestro trabajo, desde un punto de vista biológico y médico, presentan un tercer sexo, un sexo indefinido, un trastorno del desarrollo sexual, genitales ambiguos ${ }^{45}$ o, en general, cuerpos sexuados ${ }^{46}$.

Por todo lo cual desde finales del 2013, y gracias a la reciente normativa aprobada por Alemania en esta materia, Europa ya cuenta con precedentes que paulatinamente van a ayudar a romper, desde los distintos países miembros, con las barreras que ancestralmente han rodeado a estos seres humanos, al no existir hasta ahora una definición jurídica expresa que regulara los derechos de los sujetos que nacían con ambigüedad genital o con anomalías congénitas que les impidieran el normal desarrollo de sus órganos sexuales, ya fueran estos femeninos o masculinos. Este hecho ha propiciado que desde abril del 2014 el tribunal supremo de países como la India, donde recordemos que las relaciones homosexuales aún hoy son ilegales, reconozca expresamente la igualdad de

45 Cf. Adriana Agramonte, supra, nota 1. Cf. también Francisca Ugarte y Carolina Sepúlveda, supra, nota 1. Págs. 578-583.

46 Sobre el alcance de este último término clínico, véase Anne Fausto Sterling. Cuerpos SEXUAdos. LA POLÍTICA DE GÉNERO Y LA CONSTRUCCión DE LA SEXUALIDAD. Melusina. (2006). 
derechos y no discriminación entre personas transexuales o llamadas de "tercer sexo", por entender que como ciudadanos tienen el derecho humano a escoger su género en condiciones de igualdad respecto al resto.

Consideramos que todas estas reformas legislativas surgidas a nivel internacional, en un corto espacio de tiempo, tendrán su repercusión en España, donde se deberá adaptar la legislación matrimonial vigente hasta ahora a la realidad social que nos rodea. Así como ya advirtiera Patricia Panero ${ }^{47}$, desde la reforma introducida con la aprobación de la Ley 13/2005 de 1 de julio, por la que se modifica el Código Civil en materia de derecho a contraer matrimonio ${ }^{48}$, se ha extendido una nueva terminología en nuestro ordenamiento jurídico español que incluye otras relaciones frecuentes surgidas de forma paralela al matrimonio; concretamente, nos estamos refiriendo a las parejas de hecho, las uniones libres, la convivencia more uxorio, así como incluimos las conocidas actualmente como parejas intersexuales, en los términos que hemos venido definiendo.

En suma, podemos concluir afirmando que desde el 2005 el legislador español ha sido consciente de las transformaciones que están rodeando a la familia y, especialmente en lo que se refiere al matrimonio, favoreciendo un marco legislativo en el que no quepa discriminación alguna por razón de sexo o género. Muestra de ese deseo de adaptarse paulatinamente a la realidad social, lo encontramos en la propia exposición de la citada ley, cuando literalmente se recuerda que:

Tampoco en forma alguna cabe al legislador ignorar lo evidente: que la sociedad evoluciona en el modo de conformar y reconocer los diversos modelos de convivencia, y que, por ello, el legislador puede, incluso debe, actuar en consecuencia, y evitar toda quiebra entre el Derecho y los valores de la sociedad cuyas relaciones ha de regular (...) La convivencia como pareja entre personas del mismo sexo basada en la afectividad ha sido objeto de reconocimiento y aceptación social creciente, $y$ ha superado arraigados prejuicios y estigmatizaciones. Se admite hoy sin dificultad que esta convivencia en pareja es un medio a través del cual se desarrolla la personalidad de un

47 Véase Patricia Panero Oria. El concubinato romano como antecedente de las actuales parejas de hecho. RIDrom. Revista Internacional de Derecho Romano 5. 2010, Págs 92-125.

$48 C f$. Ley 13/2005, de 1 de julio. Por la que se modifica el Código Civil en materia de derecho a contraer matrimonio. Julio 2 del 2005. воE 157. Disponible en http://www.boe.es/boe/ dias/2005/07/02/ pdfs/A23 632-23634.pdf amplio número de personas, convivencia mediante la cual se prestan entre sí apoyo emocional y económico, sin más trascendencia que la que tiene lugar en una estricta relación privada, dada su, hasta ahora, falta de reconocimiento formal por el Derecho.

Aceptándose, en consecuencia, que esta percepción innovadora no solo se produce en la sociedad española de comienzos del siglo XxI, sino también en ámbitos más amplios y desde décadas anteriores, como se refleja en la Resolución del Parlamento Europeo, de 8 de febrero de 1994, en la que se solicitaba formalmente a la Comisión Europea que presentase una propuesta de recomendación para poner fin a la prohibición de contraer matrimonio que hasta entonces tenían las parejas del mismo sexo, garantizándoles plenos derechos así como los beneficios asignados al matrimonio, en condiciones de plena igualdad.

\section{REFERENCIAS}

Adriana Agramonte-Machado. Tratamiento quirúrgico de los genitales ambiguos: fundamentos e implicaciones psicológicas y sexuales. Revista Cubana de EndoCRINOLOGía 17(3). Sep.-dic. 2006. Disponible en http://scielo.sld.cu/scielo.php?script=sci_arttext\&pi$\mathrm{d}=$ S156129532006000300004

Anne Fausto-Sterling. Cuerpos sexuados. La política DE GÉNERO Y LA CONSTRUCCIÓN DE LA SEXUALIDAD. Melusina. (2006).

Biondi Biondo. Il Diritto Romano cristiano iII. Giuffrè. (1954).

Danilo Dalla. L'Incapacità sessuale in Diritto Romano. SEMINARIO GIURIDICo DELLA UNIVERSITÀ DI BOLOgNa 76. (1978).

Dora Delapuerta-Montoya. Estudio sobre el Edictum de Adtemptata Pudicitia. Tirant Lo Blanch. (1999).

Elisa Muñoz-Catalán. El matrimonio romano en ausencia de facultades físicas: Demencia, senectud y minoría de edad. e-SLegal History Review 18. (2014).

Elisa Muñoz-Catalán. Controversias jurídicas en torno a los impedimentos romanos y la intersexualidad. RJUAM. Revista Jurídica de la Universidad Autónoma DE MADRID 29. 2014.

Francisca Ugarte y Carolina Sepúlveda. Estudio del recién nacido con ambigüedad genital y gónadas palpables. Revista Chilena de pediatría 78(6). 2007. Págs. 578-583. Disponible en http://www.scielo.cl/pdf/rcp/ v78n6/art02. Pdf 
Juan Carlos Ghirardi. Regulación jurídica de las conductas sexuales extramatrimoniales en el Derecho Romano. RGDR. Revista General de Derecho Romano 5. 2005. Págs. 1-49.

Ley 13/2005, de 1 de julio. Por la que se modifica el Código Civil en materia de derecho a contraer matrimonio. Julio 2 del 2005. воE 157. Disponible en http://www.boe. es/boe/ dias/2005/07/02/ pdfs/ A23 632 - 23634.pdf

María José Bravo Bosch. Algunas consideraciones sobre el Edictum de Adtemptata ad pudicitia. AAVv, ACTAS DEL iI Congreso Iberoamericano de Derecho RomaNO. (1998). Págs. 41-43.

María Lourdes Martínez de Morentín. De la cura furiosi en las XII Tablas, a la protección del disminuido psíquico en el Derecho Actual (A propósito de la sTs de 20 de noviembre de 2002). RGDR. Revista General DE DEReCho Romano 4. 2005. Págs. 1-66.
Miguel Falçao. LAS PROHIBICIONES MATRIMONIALES DE CARÁCTER SOCIAL EN EL IMPERIO ROMANO. Universidad de Navarra. (1973).

Olís Robleda. El matrimonio en Derecho Romano. ESENCIA, REQUISITOS DE VALIDEZ, EFECTOS, DISOLUBILIDAD. Università Gregoriana. (1970).

Paola Borrelli. Il divieto di matrimonio tra tutore e pupilla. labeo. Rassegna di Diritto Romano 43. 1997.

Patricia Panero-Oria. El concubinato romano como antecedente de las actuales parejas de hecho. RIDROM. REVISta Internacional de Derecho Romano 5. 2010. Págs 92-125.

Riccardo Astolfi. Il matrimonio nel Diritto Romano ClAssico. Cedam. (2006).

Saara Lilja. Homosexuality in Republican and AugusTAN Rome. Societas Scientiarum Fennica. (1983). 